\title{
IDENTIFIKASI PEMANFAATAN ARKADE DAN IMPLEMENTASI GSB NOL DI JAKARTA BARAT
}

\author{
Theresia Budi Jayanti $^{1}$, Irene Syona Darmady ${ }^{2}$, Danang Priatmodjo ${ }^{3}$ \\ 1,2,3. Prodi Arsitektur, Fakultas Teknik, Universitas Tarumanagara \\ Jl. Letjen S. Parman No. 1 Jakarta Barat \\ Email : theresiaj@ft.untar.ac.id
}

\begin{abstract}
Abstrak
Dalam Perda No. 1 Tahun 2014 tentang RDTR dan PZ Provinsi DKI Jakarta terkait lebar rencana jalan dan Garis Sempadan Bangunan (GSB) telah diatur dengan jelas sehingga terdapat ruang milik, ruang manfaat, dan ruang pengawasan jalan dapat teratur, nyaman, dan aman. Namun, terkait kawasan tanpa GSB atau GSB nol dan pemanfaatan ruang kawasan dengan arkade belum terdapat arahan yang jelas. Pada kondisi terkini ada lokasi tertentu yang menerapkan GSB nol berdasarkan peraturan dan ada yang berdasarkan kebutuhan. Pelaksanaan studi ditujukan untuk dapat mengidentifikasi lokasi tertentu di Jakarta Barat yang menerapkan GSB nol ataupun arkade guna menemukan aspek-aspek apa saja yang mempengaruhi pemanfaatan arkade dan GSB nol. Metode observasi lapangan dan mapping digunakan untuk mencapai tujuan tersebut dan mendapat gambaran studi yang menyeluruh. Hasil temuan studi menunjukkan terdapat pola-pola penerapan arkade dan GSB nol yang tidak kontinu sehingga perlu upaya usulan baik untuk penataan ataupun masukan bagi perangkat peraturan dalam rangka menjaga kesinambungan streetscape kawasan.
\end{abstract}

Kata kunci: arkade, GSB nol, ruang kota.

\section{Abstract}

Title: Identification of Arcade Utilization and Implementation of Zero Setbacks in West Jakarta

Perda No. 1 - 2014 about Jakarta's Zoning Regulation mentioned about guidance which control building setback, streets, and right of way; in the way to achieve well-ordered cityscape in terms of urban design and architecture. However, there are unclear statement about area characterized with arcade and zero setbacks. In actual condition, there is location dominated by zero setbacks appearance based on necessary needs. This issue trigerred visual cluttering in cityscape. Based on that condition, this study tried to understand and identify location in administrative West Jakarta area which indicate arcade and zero setbacks due to its affected aspects. Site observation and mapping used as a method to finding data and analyze the process to get overall trend and tendency. Findings about this study represent such condition wtih incontinuity pattern about arcade and zero setbacks in some area or corridor. Proposal about spatial planning in conclusion of this study role as suggestion to evaluate the regulation.

Keywords: arcade, zero setbacks, cityscape.

\section{Pendahuluan}

Dalam suatu persepsi tentang pembentukan sebuah kota, kota tersusun dari beberapa elemen penting, antara lain ruang publik dan jalur sirkulasi termasuk jalur pedestrian (Lynch,1960). Penyediaan jalur pedestrian yang lebar, menerus dan terintegrasi dengan bangunan pada ruang pengawasan jalan dan ruang garis sempadan bangunan dapat berwujud suatu arkade atau area GSB nol. Menurut Perda Nomor 7 Tahun 2010 Tentang Bangunan Gedung di Wilayah DKI Jakarta menyatakan bahwa GSB nol adalah ketiadaan batas antara bangunan dengan 
sekitarnya atau artinya GSB (Garis Sempadan Bangunan) berimpit dengan GSJ (Garis Sempadan Jalan) yang juga merupakan batas kepemilikan lahan (property line).

Sebuah jalur pedestrian yang menerus dan terintegrasi atau berhimpitan dengan bangunan juga dapat pula membentuk sebuah ruang arkade. Menurut (Curl, 2006) dan (Harris, 1975) arkade merupakan jalur pejalan kaki yang beratap; sebuah ruang dengan atap dibentuk oleh jajaran dan serangkaian konstruksi lengkung yang ditumpu di atas pilar menempel atau berdiri sendiri dari dinding dan biasanya berada di area pertokoan atau perkantoran.

Dalam konteks perancangan dan penataan kota, sebuah jalur pedestrian dengan karakter ber GSB nol maupun arkade dapat dianalogikan sebagai elemen path. Menurut Kevin Lynch dalam Image of The City (Lynch,1960), path adalah jalur pergerakan di dalam kota yang berupa gang, jalanan, rel kereta api, jalan raya, kanal dan sejenisnya. Paths dapat memiliki identitas yang lebih baik jika memiliki tujuan yang jelas, penampakan yang jelas dan terintegrasi dengan bangunan di samping kanan atau kirinya. Keberadaan fungsi tertentu terhadap sebuah paths misal seperti komersial diyakini akan memberikan kenyamanan maupun keamanan bagi para pengguna jalan serta menghidupkan ruang suatu kota.

Meninjau dari beberapa literatur dan definisi di atas kondisi ideal bagi sebuah ruang arkade maupun area ber GSB nol antara lain; (1) memiliki keserasian dengan bangunan yang bersisian, (2) memiliki karakteristik tampilan seperti material, warna, deretan pilar, ukuran bangunan, bukaan dinding, pintu masuk, jendela, serambi atau beranda, (3) memiliki jalur yang jelas (menerus). Kesinambungan dari ketiga faktor tersebut akan membentuk ruang pelintas dan skyline bangunan yang dapat menimbulkan rasa ketertarikan (Fadhilla, 2017). Keselarasan skyline bangunan di sepanjang jalur/ path (dalam konteks arkade dan GSB nol) akan memberikan kontribusi pada wajah kota/ streetscape kawasan yang baik nan estetis serta mendukung kenyamanan bagi pelintas atau pengguna ruang kota. Oleh karena itu, optimalisasi pemanfaatan atas arkade dan GSB nol dinilai penting bagi wajah kawasan (NACTO, 2013).

Pentingnya kesinambungan path dalam bentuk pemanfaatan pada ruang arkade dan GSB nol terhadap streetscape juga dirumuskan dalam berbagai pedoman penataan. Salah satunya yang diterbitkan oleh New York City Planning pada tahun 2019. Pemerintah Provinsi DKI Jakarta juga memiliki Perda No.1 Tahun 2014 tentang RDTR dan PZ terkait lebar rencana jalan dan Garis Sempadan Bangunan (GSB) telah diatur dengan jelas sehingga terhadap ruang milik, ruang manfaat, ruang pengawasan jalan dapat teratur, nyaman, dan aman. Namun, terkait GSB nol dan pemanfaatan ruang dengan arkade belum diatur. Dalam rangka evaluasi dan menyusun sebuah peraturan terkait hal tersebut maka secara proses diperlukan sebuah kajian pendahuluan sebagai langkah awal dan masukan. Hal ini juga merupakan hasil wawancara pada Juli 2019 dengan Dinas Tata Ruang Pemprov DKI Jakarta.

Wilayah Jakarta Barat merupakan salah satu wilayah administratif di DKI Jakarta yang memiliki beberapa koridor dengan karakter arkade dan GSB nol yang dominan bila dibandingkan dengan kawasan lain. Namun, bila ditinjau dari sisi 
pemanfaatannya tidak optimal. Dalam artian ditemukan kondisi yang secara fisik tidak berkesinambungan dan secara aktivitas tidak hidup sebagaimana yang dimaksud oleh Kevin Lynch tentang paths. Hal ini mengakibatkan area yang memiliki karakter arkade dan GSB nol di Jakarta Barat memiliki streetscape kawasan yang tidak estetis, tidak nyaman oleh para pelintas atau pengguna ruang kota, dan jauh dari kondisi ideal.

Studi ini bertujuan untuk mengidentifikasi karakter dari pemanfaatan arkade dan GSB nol dari beberapa area/ koridor di wilayah Jakarta Barat guna menguraikan aspekaspek apa saja yang mempengaruhi pemanfaatan arkade dan GSB nol. Hal tersebut dirumuskan agar didapatkan gambaran utuh terkait kondisi, potensi, dan tantangan di lapangan sehingga hasil studi dapat menjadi usulan bagi penataan kawasan atau pertimbangan/ masukan bagi penyusunan Peraturan Gubernur terkait koridor jalan yang memiliki pemanfaatan arkade atau GSB nol.

\section{Metode}

Metode yang digunakan dalam penelitian ini adalah metode kualitatif dengan teknik deksriptif. Adapun karakteristik penelitian yaitu sebagai berikut; pendekatan kualitatif deskriptif pada penelitian ini bertujuan mendekripsikan secara sistematis, faktual, dan akurat mengenai karakter kawasan tertentu yang menerapkan arkade dan GSB nol. Dengan metode kualitatif, penelitian ini membutuhkan pengumpulan data berupa pengamatan lapangan/ observasi, dan juga survey agar semua data saling terkonfirmasi dan dapat diperiksa secara silang.

Pengumpulan data dilakukan melalui studi data LRK terdahulu terkait implementasi arkade dan GSB nol khususnya di wilayah Jakarta Barat. Diperlukan kriteria pemilihan lokasi dalam menentukan sampel lokasi di wilayah Jakarta Barat. Kriteria pemilihan lokasi didasari atas tinjauan kebijakan serta tinjauan literatur yang sudah dilakukan. Kriteria yang menjadi penentu pemilihan lokasi diantaranya adalah: (1) data LRK terdahulu, (2) koridor yang dinamis (memiliki Perubahan Fungsi Zonasi), (3) memiliki fungsi berupa perkantoran, perdagangan dan jasa, (4) pusat kegiatan kawasan, (5) kawasan berorientasi transit, (6) kawasan dengan ketentuan TPZ (cagar budaya dan berpola pita). Berdasarkan kriteria tersebut, ruang lingkup studi mencakup 5 koridor jalan, antara lain: Jalan Pintu Besar Selatan, Jalan Gajahmada (Tamansari), Jalan Mangga Besar Raya, Jalan KH. Moch Mansyur, Jalan Jembatan Besi.

Setelah menentukan 5 lokasi wilayah pengamatan, dilakukan observasi langsung dilapangan. Hal ini dilakukan untuk melakukan validasi terhadap data yang diperoleh dari peta LRK dan citra satelit. Data lapangan diperoleh melalui pengamatan lapangan secara bertahap, didahului dengan observasi awal secara menyeluruh terkait eksisting implementasi arcade dan GSB nol pada koridor jalan. Pada observasi ini diperoleh gambaran mengenai kondisi arkade dan GSB nol seperti kemenerusan, dimensi serta pemanfaatan.

Pengolahan data hasil survey lapangan dilakukan dengan teknik mapping dan infografis. Analisis data dilakukan dengan pengelompokan data berdasarkan aspek temuan di lapangan. Analisis berfokus aspek-aspek apa saja yang mempengaruhi pemanfaatan arkade dan GSB nol di lokasi terpilih. Hal tersebut dilakukan sehingga mendapatkan gambaran terkait kondisi, 
potensi dan tantangan yang ada di lokasi terpilih sehingga dapat merumuskan konsep penataan kawasan.

\section{Pembahasan}

Identifikasi terkait karakter penerapan arkade dan GSB nol pada lokasi terpilih menjadi sasaran pertama dalam pembahasan. Hal tersebut dilakukan sebagai upaya untuk dapat memahami secara menyeluruh kondisi lapangan; guna menemukan aspek-aspek apa saja yang mempengaruhi pemanfaatan arkade dan GSB nol. Temuan atas aspek terkait diperuntukan menjadi pedoman terkait usulan penataan maupun masukan yang menjawab tujuan studi.

Dalam mengidentifikasi pemanfaatan arkade dan implementasi GSB nol di 5 koridor jalan, terdapat beberapa hal/karakteristik yang menjadi temuan di lapangan, yaitu: profil penerapan arcade dan GSB Nol, klasifikasi pola penerapan serta pemanfaatan arkade dan GSB nol. Pada klasifikasi pola penerapan dan pemanfaatan arkade dibahas berdasarkan aspek lokasi dan aspek bentuk atau langgam. Sedangkan klasifikasi pola penerapan dan pemanfaatan dibahas berdasarkan aspek fungsi lahan dan sirkulasi.

Profil Karakter Penerapan Arkade dan GSB Nol

Pembahasan mengenai karakter penerapan arkade dan GSB nol dijabarkan atas beberapa koridor pengamatan. Pemilihan koridor dalam kawasan ditentukan berdasarkan proses identifikasi atas dokumen LRK terdahulu, kondisi pemanfaatan lahan, aktivitas kawasan, sirkulasi transportasi dan parkir, serta infrastruktur kawasan. Dengan demikian, maka berikut beberapa koridor kawasan yang terpilih sebagai studi kasus: Jalan Pintu Besar Selatan, Jalan Gajah Mada, Jalan Raya Mangga Besar, Jalan K.H. Moch Mansyur. 


\section{Jalan Pintu Besar Selatan}

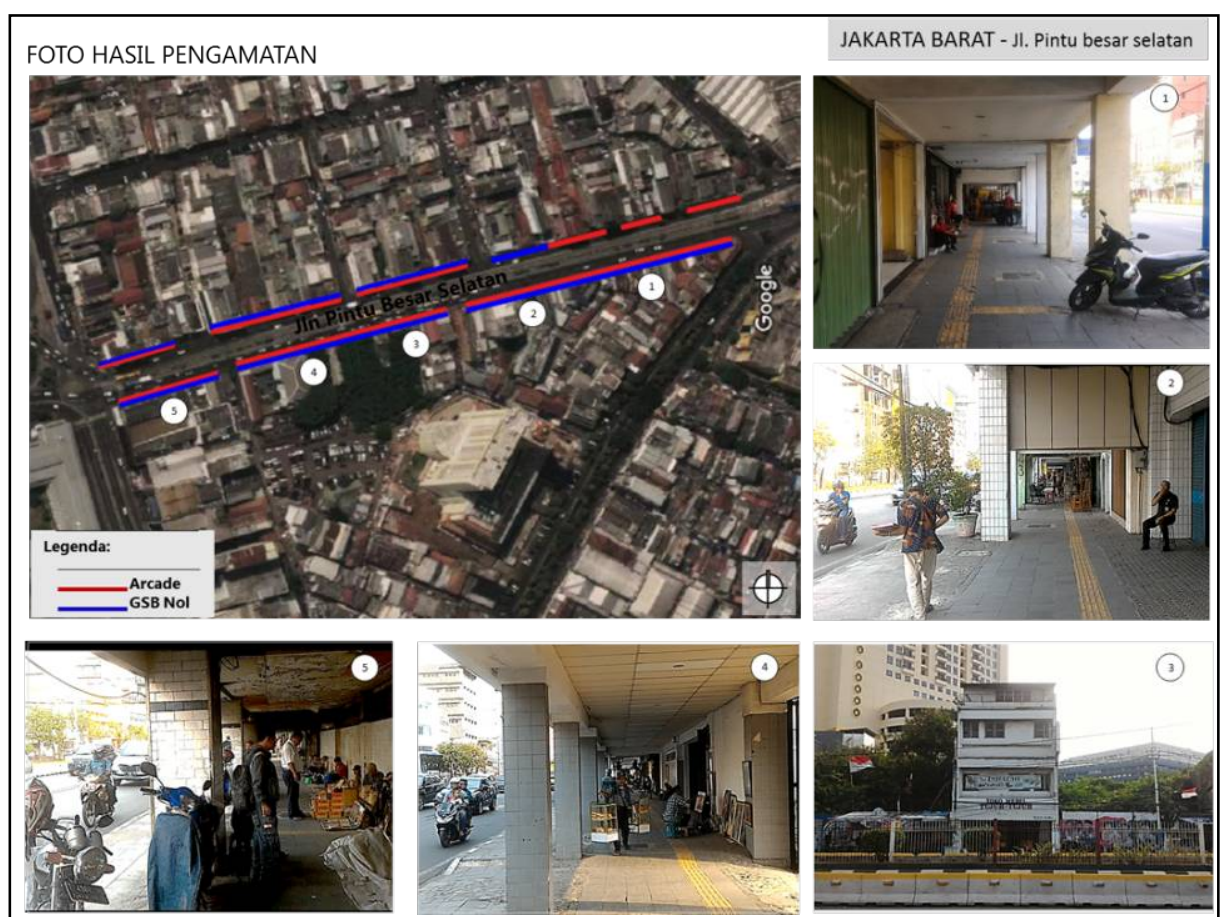

Gambar 1. Mapping hasil survey Jl. Pintu Besar Selatan Sumber: Hasil olahan penulis, 2019

Karakter koridor Jalan Pintu Besar Selatan didominasi oleh bangunan dengan GSB nol dan arkade dengan pengunaan lahan yang hampir sejenis (toko, ruko) namun sebagian besar tidak beroperasi. Selain itu juga memiliki tipe lebar lahan yang hampir sama dan mayoritas bangunan tersebut merupakan bangunan lama. Lebar arkade sekitar $2 \mathrm{~m}-3 \mathrm{~m}$ dengan tinggi yang bervariatif dari $1,8 \mathrm{~m}, 2,3 \mathrm{~m}, 3,2 \mathrm{~m}$ hingga 6m. Tipe arkade pada umumnya tipe berkolom dengan modul kolom $4 m-6 m$. Mayoritas bangunan berarkade berada pada jalan ini dan merupakan bangunan pada era 1960an. Pada kondisi terkini, ruang arkade pada koridor ini diokupansi oleh pedagang kaki lima dan parkir kendaraan sehingga mengganggu mobilitas orang. 


\section{Jalan Gajah Mada}

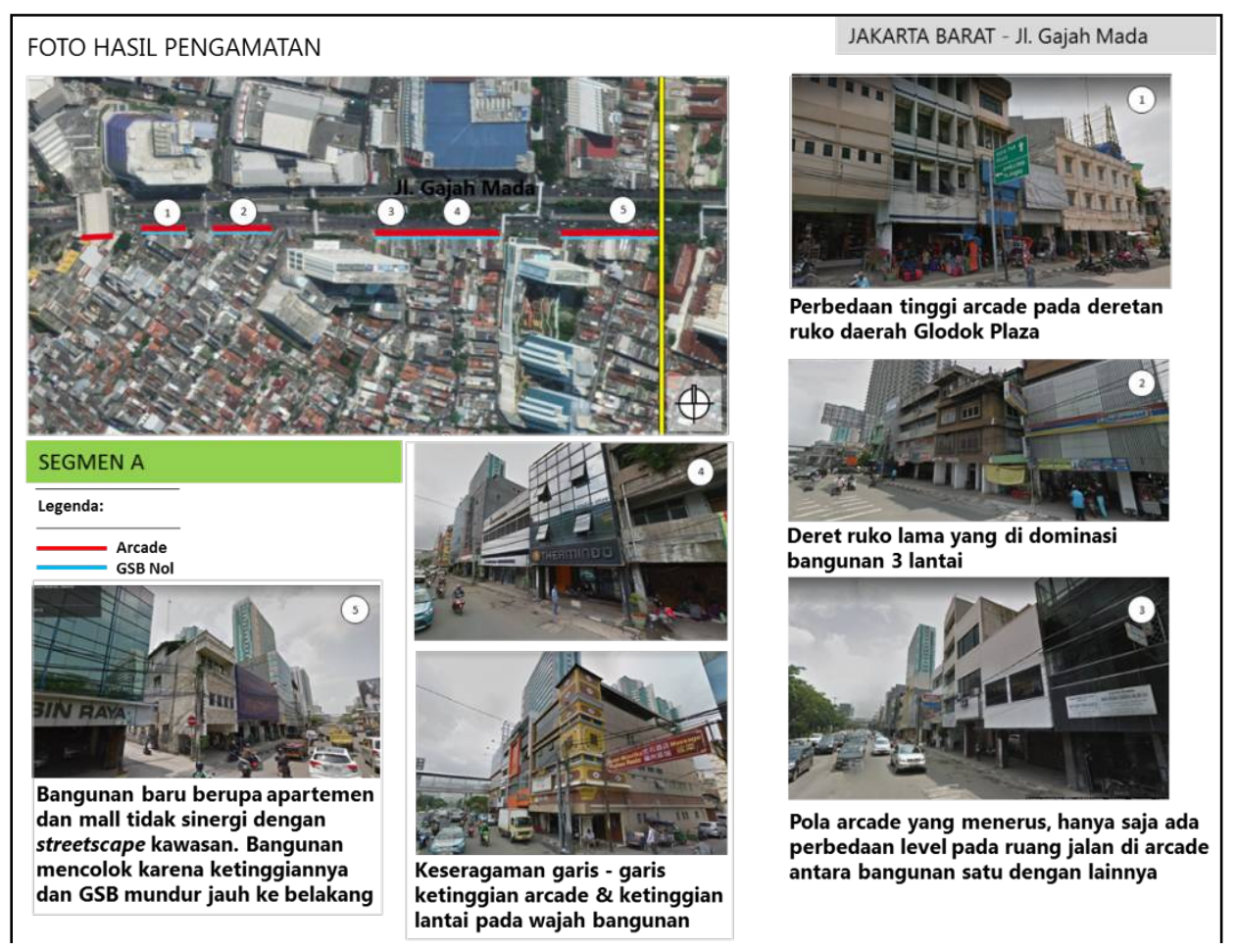

Gambar 2. Mapping hasil survey Jl. Gajah Mada

Sumber: Hasil olahan penulis, 2019

Pemanfaatan penggunaan lahan dengan potensi untuk aktivitas komersial, perdagangan dan jasa yaitu berupa rumah makan, kantor, ruko, toko, bank, money changer, dll. Apabila ditinjau dari jumlah lapis bangunan, maka pada koridor pengamatan didominasi ketinggian 3-5 lantai, dengan rata-rata 4 lantai. Karakter dominan di koridor Jl. Gajah Mada adalah GSB nol sekaligus berarkade (berkolom). Ada pula Bangunan yang menggunakan GSB nol cenderung menambahkan teritis atau lantai 2 yang didorong maju sehingga terkesan sebagai arkade. Tipe arkade di koridor pengamatan rata-rata berkolom. Ditemukan beberapa perpajangan atap berupa teritis yang terkesan sebagai arkade. Pada koridor jalan ini pola arkade tidak sepenuhnya menerus. Ada pola yang terputus pada segmen tertentu. Tinggi ruang arkade pada koridor Jalan Gajah Mada bervariasi; yaitu antara 2,5m - 3 atau $4 \mathrm{~m}$ (ratarata $3 \mathrm{~m})$. Lebar arkade rata-rata; 1,5$2,5 \mathrm{~m}$

\section{Jalan Raya Mangga Besar}

Pada Jalan Raya Mangga Besar, pemanfaatan penggunaan lahan dengan potensi untuk aktivitas komersial / perdagangan dan jasa yaitu berupa rumah makan, penginapan / hotel, ruko, toko, bank, dll. Karakter dominan di koridor Jl. Raya Mangga Besar adalah GSB nol, bahkan ditemui GSB nol dengan pola menerus sejauh $75 \mathrm{~m}-220 \mathrm{~m}$. Penggunaan arkade pada koridor jalan ini sangat jarang ditemui. Banyak bangunan menggunakan teritis untuk memberi kesan arkade, atau lantai atasnya dibuat maju sejauh kira-kira $80 \mathrm{~cm}-$ $100 \mathrm{~cm}$. Bangunan yang menggunakan GSB nol cenderung menambahkan teritis atau lantai 2 yang di dorong maju sehingga terkesan sebagai arkade. 
Dibutuhkan peraturan yang terkait karena dalam perkembangannya GSB dengan GSB nol maupun arkade, nol dibangun tidak sama rata.

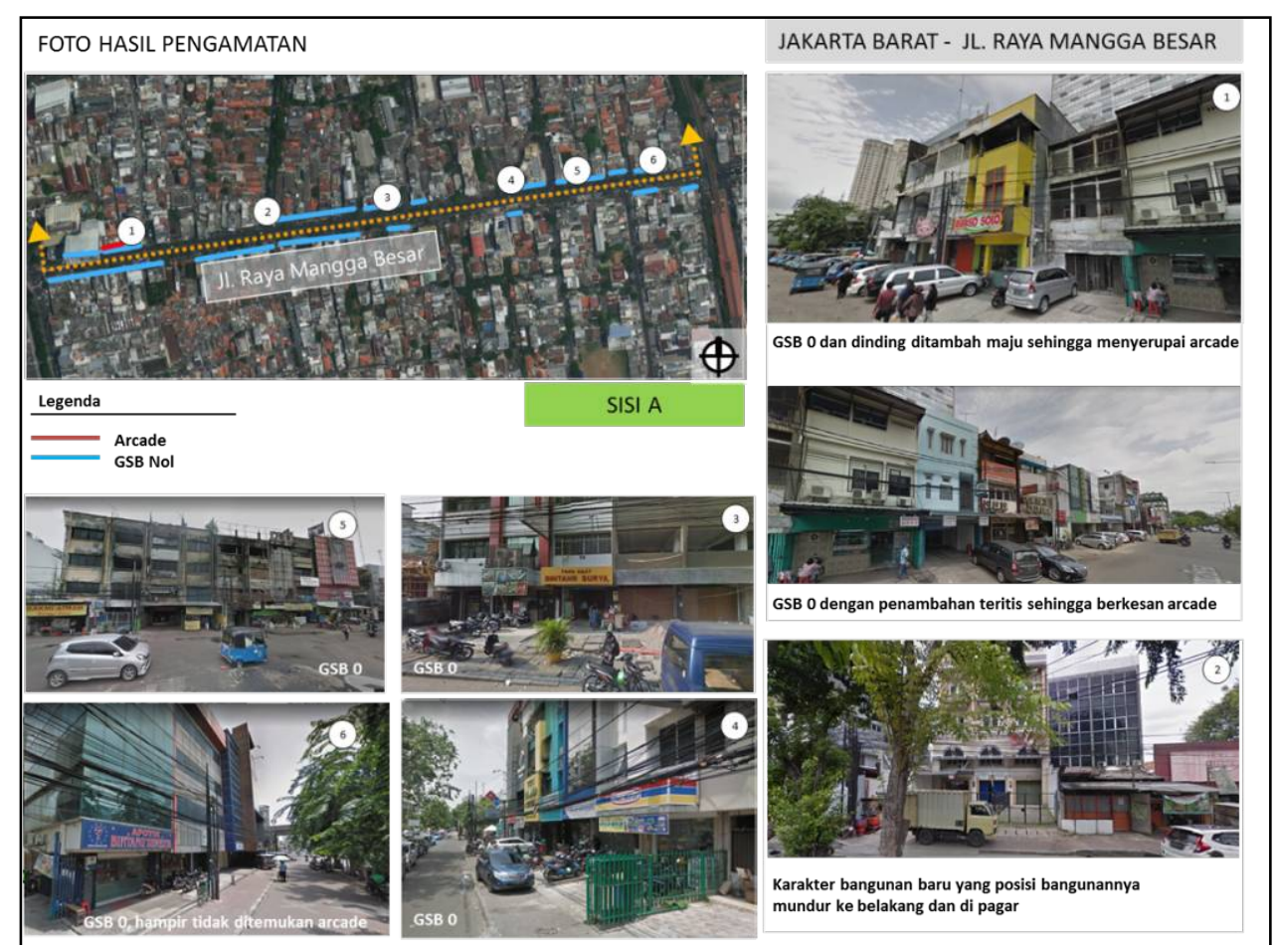

Gambar 3. Mapping hasil survey Jl. Raya Mangga Besar

Sumber: Hasil olahan penulis, 2019

\section{Jalan KH. Moch Mansyur}

Pemanfaatan penggunaan lahan dengan potensi untuk aktivitas komersial, perdagangan dan jasa yaitu berupa toko, rumah makan, kantor, bank, dll. Toko terutama di dominasi oleh pedagang eceran dan grosir. Karakter dominan di koridor Jl. KH Moch Mansyur adalah GSB nol. Ditemui beberapa deret bangunan GSB nol dengan rata-rata $25 \mathrm{~m}$. Arkade tidak ditemui sepanjang koridor pengamatan. Apabila ditinjau dari jumlah lapis bangunan, maka pada koridor pengamatan bangunan yang posisinya mundur didominasi ketinggian 3-5 lantai. Pada bangunan yang posisinya ber-GSB nol, biasanya memiliki ketinggian 1-2 lantai. Terdapat bangunan yang posisinya mundur, namun memiliki usaha informal di bagian depan bangunan, sehingga diberi atap yang cukup panjang sehingga terkesan ber GSB nol (lihat. gambar 4). 


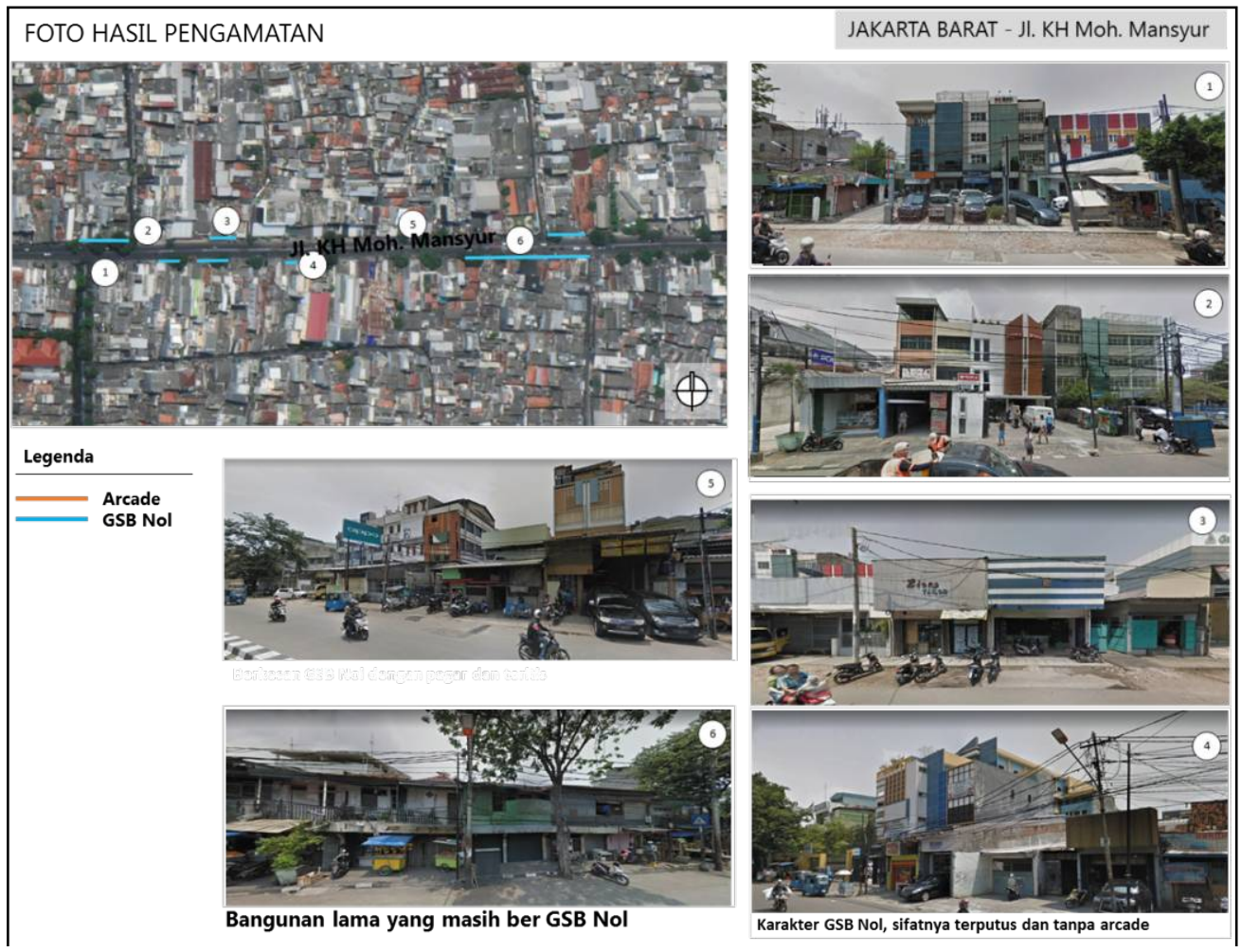

Gambar 4. Mapping Hasil Survey Jl. K.H. Moch Mansyur Sumber: Hasil Olahan Penulis, 2019

\section{Jalan Jembatan Besi II}

Jalan memiliki penggunaan lahan yang di dominasi toko, selain itu terdapat rumah makan, toko pakaian dan kebutuhan sehari-hari. Aktivitas pemanfaatan yang menjadi karakter dominan adalah toko otomotif (terutama bengkel). Apabila ditinjau dari jumlah lapis bangunan, maka pada koridor pengamatan bangunan yang posisinya mundur didominasi ketinggian 3-4 lantai. Pada bangunan yang posisinya ber-GSB nol, biasanya memiliki ketinggian 1-2 lantai. Tidak ditemui adanya arkade, hanya beberapa bangunan yang berkesan sebagai arkade. Karakter dominan di koridor Jl. Prof. Dr. Latumenten adalah GSB nol, terutama pada bangunan lama yang memiliki ketinggian 1-2 lantai. Bangunan yang mundur ke belakang atau tidak GSB nol cenderung menambahkan penutup atap hingga ke batas pagar sehingga berkesan GSB nol (lihat gambar 5). 


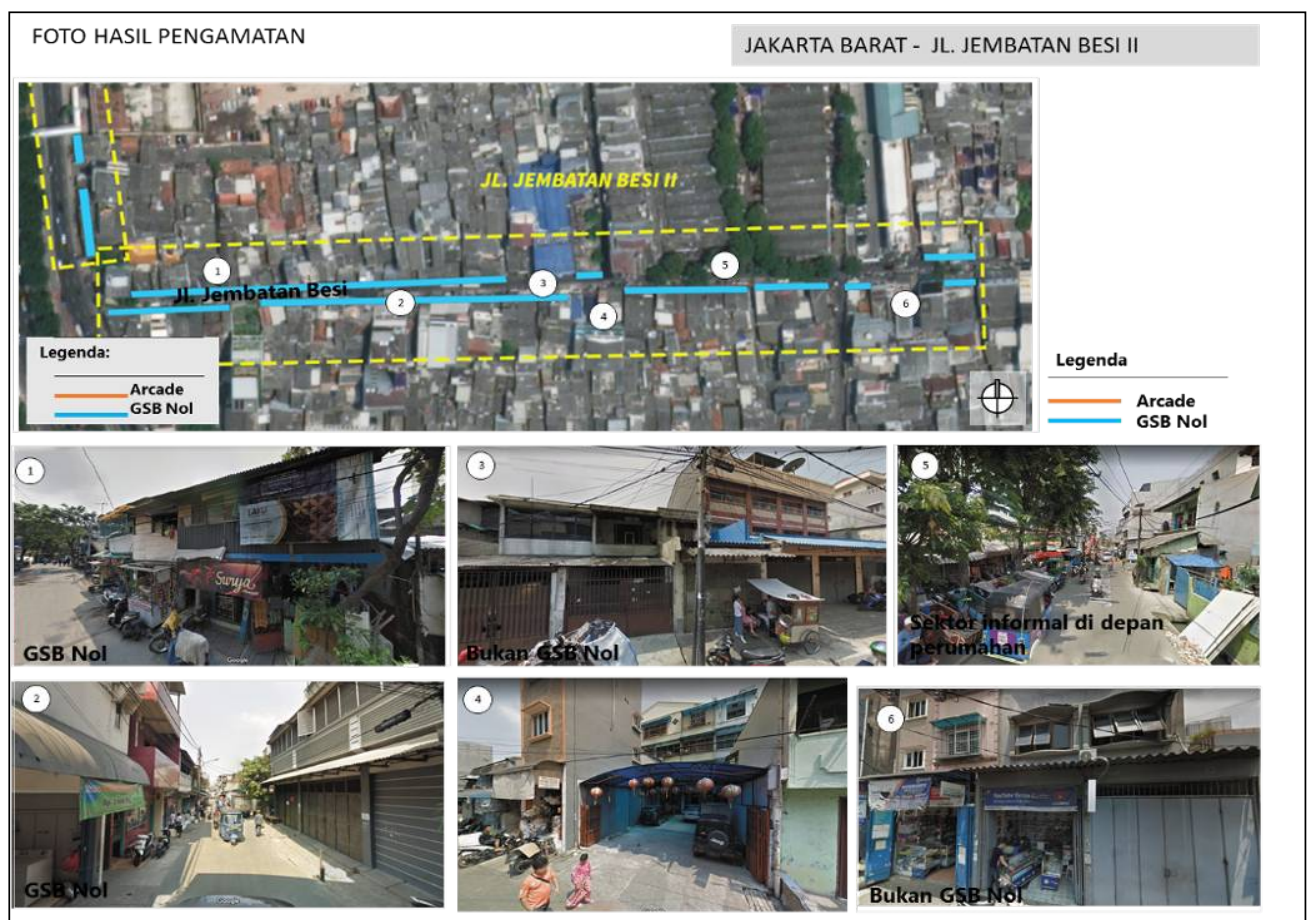

Gambar 5. Mapping hasil survey Jl. Jembatan Besi II Sumber: Hasil olahan penulis, 2019

\section{Klasifikasi Pola Penerapan Arkade dan GSB Nol}

\section{Klasifikasi Pola Penerapan dan Pemanfaatan Arkade}

Berdasarkan penjelasan dari beberapa koridor pengamatan maka dapat dilakukan pengelompokkan/ kategorisasi berdasarkan aspek untuk memudahkan pembahasan. Pola penerapan arkade berdasarkan temuan lapangan dapat diklasifikasikan dalam 2 aspek, antara lain: (1) berdasarkan lokasi, (2) berdasarkan bentuk atau langgam.

\section{Berdasarkan Lokasi}

Berdasarkan temuan lapangan, penerapan arkade dapat dibedakan atas lokasional dengan karakter (1) kawasan cagar budaya / kawasan pemugaran, (2) Kawasan non cagar budaya. Apabila mengacu dari hasil survey, implementasi koridor dengan arkade di wilayah Jakarta Barat, sebagian besar berada di kawasan cagar budaya, antara lain di Jl. Pintu
Besar Selatan, Jl. Gajahmada, Jl. Jembatan Besi. Sedangkan untuk implementasi koridor dengan arkade di kawasan non cagar budaya; pada umumnya berada di kawasan yang dekat dengan pusat kegiatan, berorientasi transit dan memiliki dinamika pada pengembangan koridor kawasan (perubahan fungsi zona menjadi komersial), misalnya Jl. Mangga Besar Raya.

Berdasarkan Bentuk atau Langgam Berdasarkan hasil survey, terdapat 2 tipe implementasi koridor dengan arkade; yaitu: (1) arkade dengan kolom, (2) arkade tanpa kolom. Pada hasil pengamatan ditemukan koridor jalan yang menerapkan prinsip arkade (dengan kolom) umumnya koridor jalan pada lokasi yang berkembang di era tahun 1950-1980 (kesejarahan), contohnya Jl. Gajah Mada. Seiring dengan perkembangan desain dan teknologi, muncul tipe arkade baru yang tidak lagi menggunakan kolom, misalnya di Jalan Mangga Besar Raya. 
Hasil temuan lapangan mayoritas menunjukkan umumnya kondisi koridor jalan yang terdapat arkade cenderung memiliki pola yang terputus-putus dan tidak memiliki keseragaman/ kontinuitas. Menurut (Schumacher, 1986) karakteristik dari semua bangunan pada keseluruhan jalan merupakan hal yang perlu dijaga keserasiannya. Untuk menjaga agar tampilan streetscape/ visual kawasan yang baik, sebagai arahan penataan; maka perlu dikaji lebih lanjut terhadap segmen jalan dalam kaitannya dengan karakter kawasan terutama di kawasan cagar budaya / kawasan pemugaran, untuk kemudian ditindak lanjuti dalam perumusan Panduan Rancang Kota (PRK) per koridor jalan. Dimana PRK tersebut didasarkan pada kasus per kasus segmen jalan bukan sebagai rekomendasi umum yang dapat diberlakukan di koridor manapun. Selain itu, pembentukan visual streetscape perkotaan diharapkan dapat menceritakan karakter dan image dari kota tersebut, mulai dari cerita historisnya, hingga gaya hidup perkotaan yang tercermin dari fasilitas dan aktifitas yang terlihat pada streetscape (Utomo, 2015)

Perihal kontinuitas ruang arkade, diperlukan panduan karakter kawasan untuk dapat menentukan sampai batas tertentu diberlakukannya arkade, dan kesamaan tinggi level ruang jalan di arkade untuk memberikan kenyamanan bagi pejalan kaki.

\section{Klasifikasi Pola Penerapan dan Pemanfaatan GSB Nol}

Pola penerapan GSB nol berdasarkan temuan lapangan dapat diklasifikasikan dalam beberapa aspek guna memahaminya. Adapun pola penerapan GSB Nol dapat diamati berdasarkan aspek: (1) fungsi lahan, (2) akses dan sirkulasi, serta (3) besaran kavling.
Berdasarkan Fungsi Lahan

Berdasarkan hasil survey awal, implementasi GSB nol yang ditinjau dari aspek fungsi/ peruntukan lahan nyatanya didominasi oleh lahan dengan fungsi: (1) campuran, (2) permukiman, (3) perdagangan dan jasa dengan pemanfaatan kegiatan eksisting yang dominan berupa komersial. Berdasarkan hasil pengamatan, ditemukan ada beberapa tipe koridor jalan yang menerapkan prinsip GSB nol, antara lain: Koridor dengan dominasi fungsi lahan komersial, perdagangan, dan jasa (Jl. Mangga Besar Raya dan Jalan K.H. Moh Mansyur). Sedangkan koridor dengan dominasi fungsi lahan hunian (Jalan Jembatan Besi, dan Jalan Krendang).

Berdasarkan Akses dan Sirkulasi

Berdasarkan hasil pengamatan, ditemukan ada beberapa tipe koridor jalan yang bangunannya menerapkan pola GSB nol, antara lain:

1. Koridor kelas jalan arteri (Contoh: Jalan Gajah Mada, Jalan Hayam Wuruk)

2. Koridor kelas jalan kolektor (Contoh: Jalan Moch Mansyur, Jalan Mangga Besar)

3. Koridor kelas jalan lingkungan (Jalan Jembatan Besi, Jalan Krendang, dsb.)

Pada koridor kelas jalan arteri ditemukan bahwa keberadaan koridor yang bangunannya ber GSB nol memungkinkan adanya pertemuan dengan kawasan yang memiliki ciriciri:

1. Memiliki intensitas pemanfaatan ruang tinggi (KDB dan KLB tinggi),

2. Merupakan pusat kegiatan kawasan (Shopping street, Entertainment street / dining street), kawasan komersial.

3. Berada di pusat kota (downtown). 
4. Dapat memiliki koneksi dengan titik transit.

Berdasarkan Besaran Kavling

Berdasarkan hasil pengamatan, ditemukan ada beberapa tipe koridor jalan yang menerapkan prinsip GSB Nol, antara lain: karakter koridor jalan yang didominasi (1) kavling kecil dengan lebar kavling maksimal $<10 \mathrm{~m}$, (2) kavling besar dengan lebar kavling $>10 \mathrm{~m}$.

Identifikasi terkait aspek-aspek tersebut menunjukkan bahwa penerapan terkait GSB nol pada koridor pengamatan lebih beragam. Secara umum temuan lapangan terkait penerapan GSB nol yang ada di deliniasi area studi memiliki karakter sebagai berikut:

1. Sebagian besar eksisting berupa ruko

2. Umumnya merupakan pusatpusat kegiatan perkantoran dan perdagangan.

Selain kedua hal di atas, ditemukan pula bahwa penerapan GSB nol umumnya masih bersifat parsial terhadap keseluruhan penggal jalan (tidak menerus/ terputus-putus). Sehingga pada kondisi demikian masih dimungkinkan adanya bangunan yang belum menerapkan GSB nol (lihat gambar 6). Bila mengacu dengan kajian referensi dalam (NYC Planning,
2019) dan (Lynch, 1960), kesinambungan/ kemenerusan arkade maupun bangunan ber GSB nol merupakan hal penting dan diperlukan untuk menunjang perlintasan pengguna, kejelasan streetscape dan identitas kawasan. Hal tersebut diutarakan pula oleh (Fadhilla, 2017) bahwa kontinuitas ruang arkade yang ditunjang oleh kualitas fisik yang baik dapat menarik minat pejalan kaki. Melalui referensi tersebut maka dapat dipahami bahwa kemenerusan atau kontinuitas ruang arkade dan GSB nol menjadi hal yang penting untuk kualitas fisik kawasan dan pemanfaatannya oleh pelintas/ pejalan kaki.

Oleh demikian, guna mengatasi masalah kemenerusan dalam artian mencegah pola yang terputus-putus seperti yang ditemukan pada 5 koridor studi kasus, maka penerapan GSB nol perlu ditinjau berdasarkan kajian karakter kawasan. Bilamana pada kawasan tersebut sudah didominasi oleh bangunan tidak ber GSB nol dan pola terputus nya terlihat jelas maka pemberlakuan peraturan GSB nol perlu meninjau karakter kawasan terlebih dahulu. Namun pada koridor yang mayoritas didominasi oleh bangunan ber GSB nol, maka pemberlakuan peraturan GSB nol dapat bersifat memberikan kejelasan. 


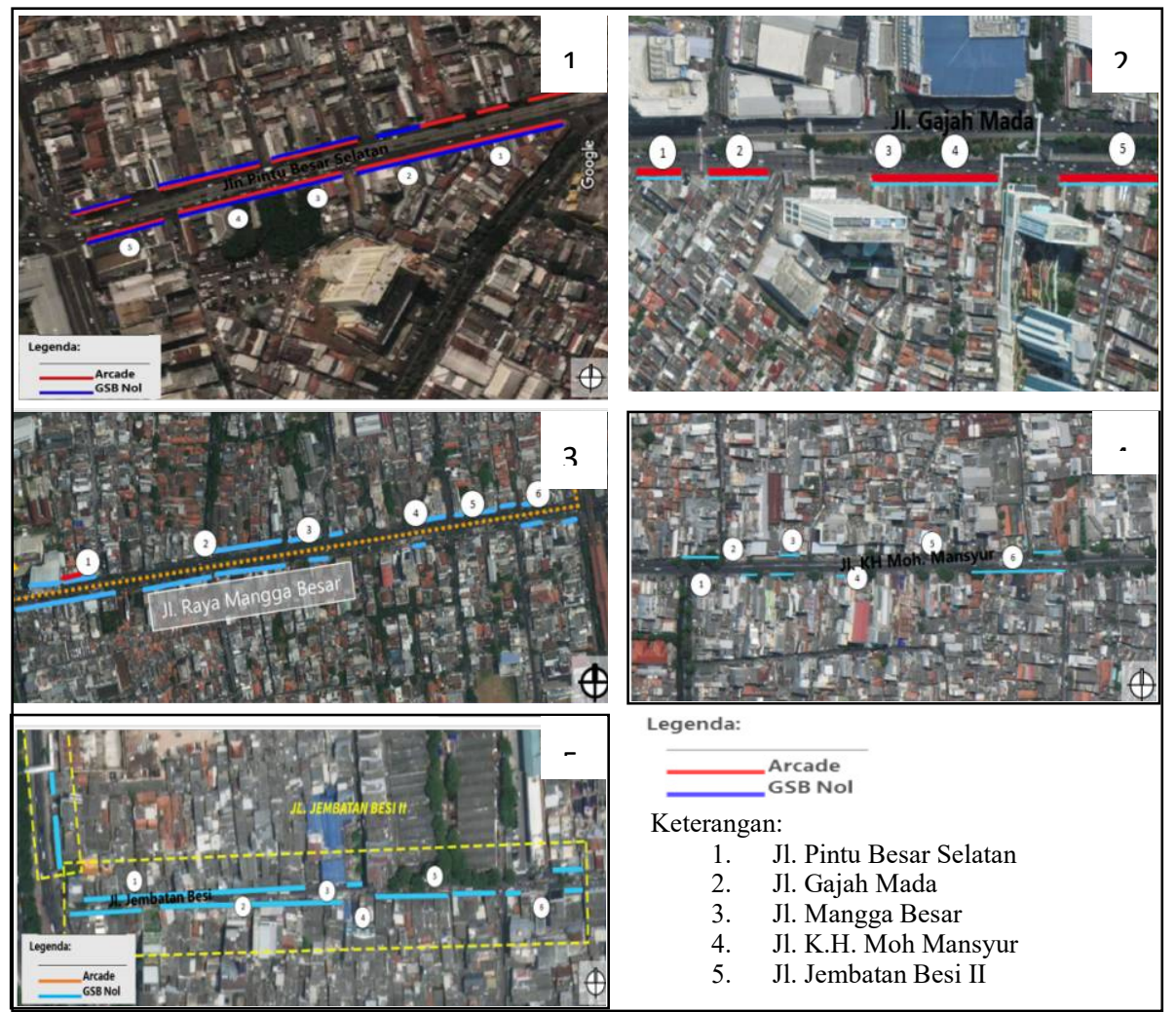

Gambar 6. Mapping penerapan GSB nol dan arkade pada area studi Sumber: Olahan penulis, 2019

Berdasarkan pemaparan dari hasil dan GSB nol dapat diilustrasikan temuan lapangan pada 5 koridor melalui gambar di bawah ini. pengamatan, maka penerapan arkade

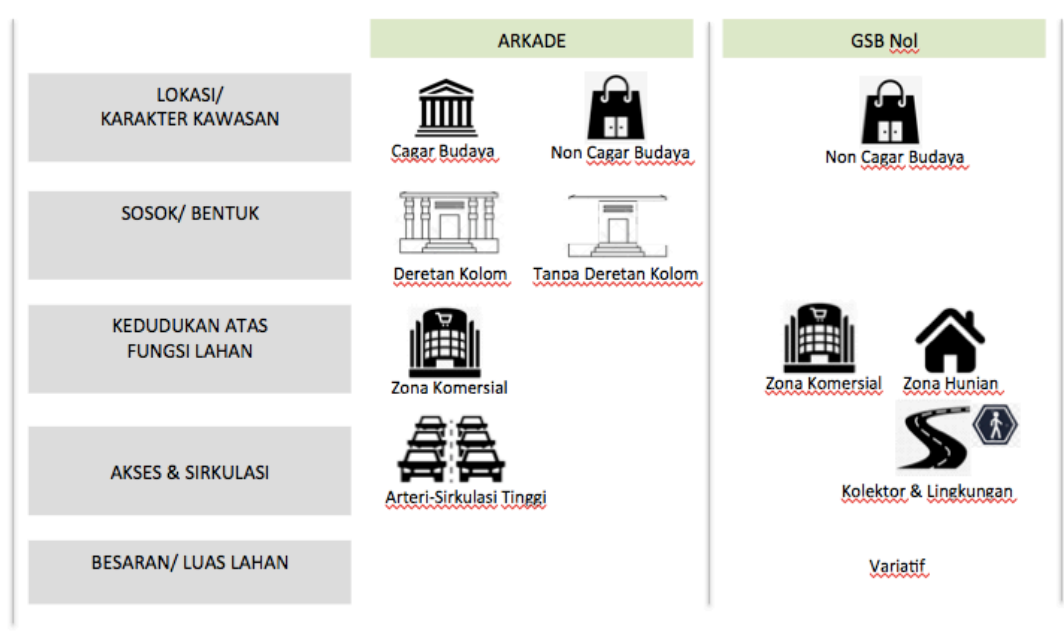

Gambar 7. Klasifikasi penerapan arkade dan GSB nol berdasarkan aspek Sumber: Olahan penulis, 2020 
Tabel 1. Tabel penerapan arkade dan GSB nol berdasarkan lokasi

\begin{tabular}{|c|c|c|c|c|c|c|c|c|c|c|c|}
\hline \multirow{2}{*}{ Aspek } & \multicolumn{2}{|c|}{ Lokasi } & \multicolumn{2}{|c|}{$\begin{array}{l}\text { Tata Guna } \\
\text { Lahan }\end{array}$} & \multicolumn{2}{|c|}{ Bentuk } & \multicolumn{2}{|c|}{ Pola } & \multicolumn{3}{|c|}{ Akses } \\
\hline & 莺 & 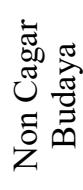 & 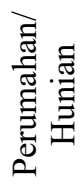 & 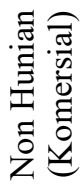 & 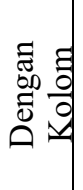 & 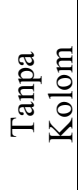 & 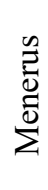 & 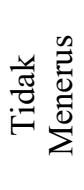 & 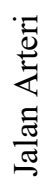 & 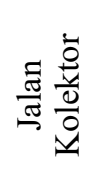 & 㺃 \\
\hline \multicolumn{12}{|l|}{ ARKADE } \\
\hline $\begin{array}{l}\text { J1. Pintu Besar } \\
\text { Selatan }\end{array}$ & $\mathrm{x}$ & & & $\mathrm{x}$ & $\mathrm{x}$ & & $\mathrm{x}$ & & $\mathrm{x}$ & & \\
\hline J1. Gajah Mada & & $\mathrm{x}$ & & $\mathrm{x}$ & & $\mathrm{x}$ & $\mathrm{x}$ & & $\mathrm{x}$ & & \\
\hline \multicolumn{12}{|l|}{ GSB NOL } \\
\hline J1. Jembatan Besi II & & $\mathrm{x}$ & $\mathrm{x}$ & & & & $\mathrm{x}$ & & & & $\mathrm{x}$ \\
\hline Jl. Mangga Besar & & $\mathrm{X}$ & & $\mathrm{x}$ & & & $\mathrm{x}$ & & & $\mathrm{x}$ & \\
\hline Jl. Moh. Mansyur & & $\mathrm{X}$ & & $\mathrm{x}$ & & & & $\mathrm{X}$ & & $\mathrm{x}$ & \\
\hline
\end{tabular}

Sumber: Olahan penulis, 2020

\section{Usulan Penataan}

Berdasarkan studi yang telah dilakukan, dapat dirumuskan rekomendasi tentang perlakuan terhadap koridor-koridor yang dalam rencana kota terdahulu (LRK) ditetapkan sebagai koridor GSB nol dengan arkade atau tanpa arkade. Dari hasil pengamatan, di berbagai koridor GSB nol ditemukan keberadaan bangunan-bangunan dibangun mundur dari GSJ, sehingga tata bangunan tidak berkesinambungan. Kondisi yang demikian ditemukan pada koridor Jalan Gajah Mada. Untuk kasus yang demikian, sebagai rekomendasi maka dimungkinkan untuk membuat bangunan tambahan agar muka bangunan rata dengan sekitarnya. Prinsip demikian juga menjadi arahan dalam (Harris, 1975) dan (Curl, 2006) terkait arkade sebagai definisi dari jalur/ ruang perlintasan pejalan kaki yang perlu berkesinambungan, memiliki level yang sama dan beratap (secara teknis dan fungsinya).

Sebagai alternatif bagi penyelesaian dari pola koridor GSB nol yang terputus-putus, maka pada sisi depan bangunan dapat dimanfaatkan sebagai ruang jeda (node) di samping jalur arkade atau jalur perlintasan orang pada koridor ber GSB nol, yang penggunaannya bersifat publik. Misalnya: sebagai privately owned public space (POPS), area parkir/ sirkulasi bersama.

Dalam kasus koridor yang telah memiliki pola arkade yang menerus namun tidak memiliki kejelasan pemanfaatan kegiatan (koridor Jalan Pintu Besar Selatan yang terletak diantara Kota Tua dan Glodok Pecinan) maka menurut (Lynch, 1960) peremajaan kawasan dengan memanfaatkan dan menambah aktivitas seperti pasar seni, pertokoan/ aktivitas belanja dapat dimungkinkan sehingga jalur arkade menjadi sebuah paths yang tidak terbengkalai dan memiliki karakter/ identitas yang menunjang kawasan. Usulan yang demikian seperti yang terlihat pada kasus di kota-kota lain di luar negeri.

Dari sisi teknis tampilan, menurut (NYC Planning, 2019) di sepanjang garis batas depan tapak (front lot line) pada koridor ber-arkade/ ber-GSB nol 
perlu memiliki tinggi permukaan lantai (peil) sama dengan permukaan lantai trotoar terdekat. Hal ini dinilai penting. Namun hal sebaliknya terlihat pada temuan lapangan; hampir seluruh koridor tidak memiliki permukaan level perlintasan, dan tinggi arkade yang sama. Oleh karena itu, hal terkait tinggi permukaan area ber-arkade/ ber GSB nol perlu menjadi poin dalam strategi penataan kawasan/ panduan penataan. Terpenuhinya aspek tersebut secara teknis diyakini dapat membuat kualitas ruang yang berbatasan dengan arkade dan GSB nol lebih baik.

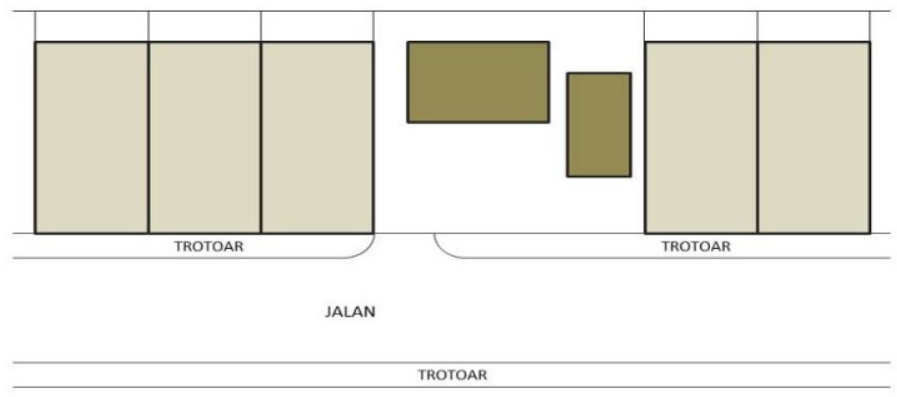

Kondisi eksisting, ada bangunan yang mundur dari GSJ

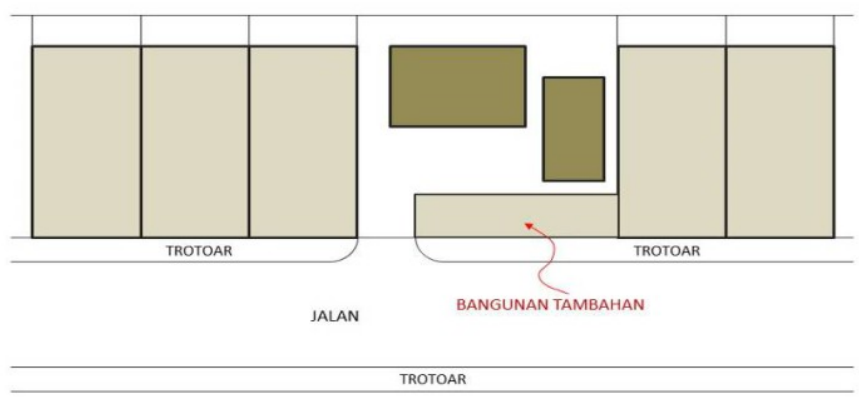

Alternatif 1: Dibuat bangunan tambahan

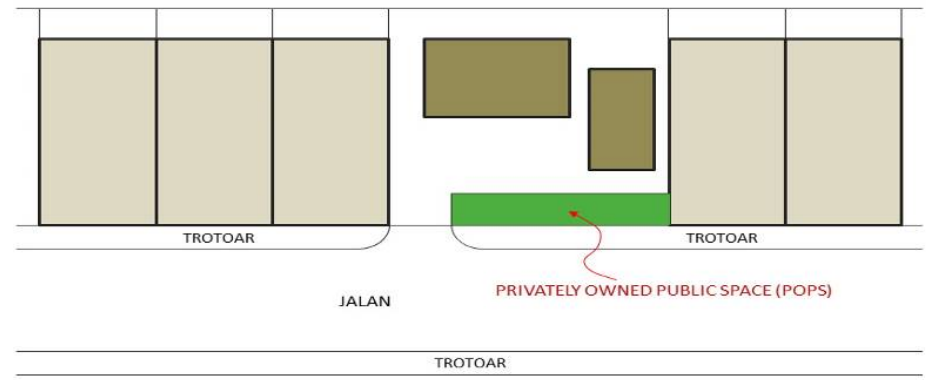

Alternatif 2: Dibuat ruang jeda berstatus POPS

Gambar 8. Usulan penerapan

Sumber: Hasil olahan penulis, 2020

\section{Kesimpulan}

Berdasarkan kajian yang telah dilakukan, yaitu studi literatur, perbandingan dengan kasus serupa di kota-kota lain di luar negeri, mempelajari Lembar Rencana Kota (LRK) terdahulu, serta melakukan pengamatan lapangan pada beberapa koridor/ kawasan tertentu di wilayah Jakarta Barat, secara umum terlihat pola yang terputus-putus (tidak memiliki kemenerusan).

Kesinambungan building line dalam sebuah koridor ber GSB nol atau 
arkade diperlukan untuk menjaga streetscape sebagai elemen pembentuk ruang kota. Pada hasil pembahasan terdapat dua implementasi arkade pada koridor sampel, yaitu arkade dengan kolom dan arkade tanpa kolom. Terkait penerapan bangunan dengan GSB nol pada area studi memiliki karakter sebagian besar berupa ruko dan pada umumnya berada di pusatpusat kegiatan perkantoran dan perdagangan.

Dapat disimpulkan implementasi arkade pada koridor pengamatan berada di kawasan cagar budaya dan non cagar budaya, mempunyai tata guna lahan dengan peruntukan komersial, mayoritas berpola menerus serta berada di jalan arteri. Sedangkan implementasi GSB nol pada koridor pengamatan mempunyai karater berada di kawasan non cagar budaya, berada di kawasan dengan peruntukan komersia / non hunian, berpola menerus dan tidak menerus, serta berada di jalan kolektor.

Berdasarkan karakter di atas, perlu usulan penataan koridor kawasan terpilih dengan tujuan untuk memperjelas dan menjaga kontinuitas streetscape dan karakter kawasan sehingga pemanfaatan koridor dapat lebih optimal. Sebagai ulusan penataan, ruang pada bangunan berGSB dimanfaatkan sebagai node / ruang jeda dengan fungsi sebagai POPS (privately owned public space) atau area parkir / sirkulasi bersama sehingga kualitas kawasan menjadi lebih baik.

\section{Ucapan Terima Kasih}

Ucapan terima kasih disampaikan kepada LPPM Untar; PT. Jakarta Konsultindo; Dinas Cipta Karya, Tata Ruang dan Pertanahan Provinsi DKI Jakarta atas bantuan baik berupa materiil maupun informasi berupa data terkait.

\section{Daftar Pustaka}

Curl, James Stevens. (2006). A dictionary of architecture and landscape architecture $(2 \mathrm{ed})$. Oxford: Oxford University Press.

Fadhilla, Fikrani, Rochani, Agus. (2017). Karakteristik koridor jalan ditinjau dari fisik ruang; studi kasus: koridor Jalan MT. Haryono Kota Kendari. Jurnal Planologi, Vol. 14, No. 1, 29-39.

Harris, Cyril M. (1975). Dictionary of architecture and construction. New York: McGraw-Hill.

Lynch, K. (1960). The image of the city. USA: Massachusetts Institute of Technology Press.

Gubernur Provinsi Daerah Khusus Ibukota Jakarta. (2010). Perda no. 7 tahun 2010 tentang bangunan gedung. Jakarta: Gubernur Provinsi DKI Jakarta.

Gubernur Provinsi Daerah Khusus Ibukota Jakarta. (2012). Perda DKI Jakarta no. 1 tahun 2012 tentang rencana tata ruang wilayah 2030. Jakarta: Gubernur Provinsi DKI Jakarta.

Gubernur Provinsi Daerah Khusus Ibukota Jakarta. (2014). Perda no. 1 tahun 2014 tentang rencana detail tata ruang dan peraturan zonasi. Jakarta: Gubernur Provinsi DKI Jakarta.

Schumacher, T. (1986). Building and street. USA: Massachusetts Institute of Technology Press.

Utomo, Heru Prasetiyo \& Mutia, Fairuz. (2018). Streetscape sebagai pembentuk karakter kawasan; studi kasus: Jalan Rungkut Madya Surabaya. Jurnal ATRIUM, Vol. 4, No. 2, 117-128. 